\author{
Divisão de Doenças de \\ Transmissão Hídrica e \\ Alimentar, Centro de Vigilância \\ Epidemiológica "Prof. Alexandre \\ Vranjac", Coordenadoria de \\ Controle de Doenças, Secretaria \\ de Estado da Saúde
}

Correspondência | Correspondence: Secretaria de Estado da Saúde de São Paulo Av. Dr. Arnaldo, $3511^{\circ}$ andar sala 135

01246-901 São Paulo, SP, Brasil

E-mail: bepa@saude.sp.gov.br

Texto de difusão técnico-científica da

Secretaria de Estado da Saúde de São Paulo.

\section{Novas estratégias para a vigilância epidemiológica da esquistossomose no estado de São Paulo}

\author{
New strategies for schistosomiasis \\ surveillance in the state of São Paulo, \\ Southeastern Brazil
}

A esquistossomose mansônica é de notificação compulsória nas áreas consideradas não endêmicas no Brasil. No estado de São Paulo, a coordenação da vigilância epidemiológica da esquistossomose é feita pela Divisão de Doenças de Transmissão Hídrica e Alimentar do Centro de Vigilância Epidemiológica "Prof. Alexandre Vranjac” (CVE), órgão da Coordenadoria de Controle de Doenças da Secretaria de Estado da Saúde (CCD/SES-SP).

Considerada uma doença negligenciada e subnotificada em todo o mundo, é ainda de importância em saúde pública, relacionada principalmente às precárias condições de vida e de saneamento básico. Segundo a Organização Mundial de Saúde (OMS), mais de 200 milhões de indivíduos no mundo estão infectados. Dados do Ministério da Saúde mostram que a esquistossomose, no Brasil, causa mais óbitos (em média, mais de 500 a cada ano) que a dengue, a leishmaniose visceral e a malária. Mais de 100 mil casos da doença são identificados a cada ano no território nacional e, os estados com maior prevalência são Minas Gerais, Bahia, Pernambuco, Alagoas e Sergipe.

Os primeiros focos de esquistossomose no estado de São Paulo ocorreram nas primeiras décadas do século XX e se intensificaram nos anos 1970, devido a migrações de populações vindas de estados do Nordeste e de alguns da região Sudeste, como Minas Gerais. Tais populações se fixavam em áreas sem infraestrutura urbana, sem saneamento e com coleções hídricas infestadas com as espécies de caramujos transmissores.

Por meio de intensos trabalhos realizados em décadas anteriores até o presente, por ações de vigilância, assistência médica e medidas ambientais, o estado de São Paulo obteve redução significativa da transmissão em suas coleções hídricas. Nos anos 1980 eram notificados 20 mil casos a cada ano, incluindo-se importados e autóctones. Na década de 1990, esse número baixou para pouco mais de 10 mil. Nos últimos anos, segundo os dados do CVE, tem sido registrado em média um total de 2 mil casos por ano, 10\% dos quais autóctones. Quando se atinge patamares representados por baixa prevalência da doença na comunidade e baixa carga parasitária dos indivíduos infectados, novas estratégias podem ser necessárias para a vigilância e controle, objetivando-se melhorar os métodos de captação precoce de casos (sintomáticos e assintomáticos) e, inclusive, a eliminação da autoctonia da doença.

Nos últimos anos, dados de levantamento planorbídico realizado pela Superintendência de Controle de Endemias (Sucen/SES-SP) mostram que 248 municípios entre os 645 do estado de São Paulo possuem criadouros das espécies transmissoras em suas coleções hídricas. Esses criadouros constituem potenciais focos de risco à doença, especialmente naqueles locais com problemas de saneamento, presença de populações migrantes (trabalhadores da construção civil, das lavouras de canade-açúcar e laranja, entre outras), em áreas de periferia urbana ou rural. Entre estes municípios, 170 registraram casos autóctones nos últimos cinco anos, sendo as regiões paulistas de maior prevalência da doença: Vale do Ribeira, Vale do Paraíba, Litoral Norte e Baixada Santista, Grande Campinas e alguns municípios da Região Metropolitana de São Paulo, incluindo a capital.

Para se atingir a eliminação da esquistossomose em áreas de baixa prevalência e baixa carga parasitária, como é a situação da grande maioria dos municípios de São Paulo, é fundamental a melhoria dos métodos diagnósticos para aumento de captação de casos sintomáticos e assintomáticos. Embasando-se em recomendações da 
OMS, em experiências bem-sucedidas no Brasil e em outros países, foram estabelecidas as seguintes novas estratégias para a vigilância da doença:

1. Aumento da suspeição médica a partir da redefinição de caso suspeito incluindo investigação diagnóstica de todo indivíduo assintomático ou com quadro clínico sugestivo das formas agudas ou crônicas, residente e/ou procedente de área endêmica para esquistossomose, com história de contato com coleções de águas potencialmente de risco (presença de caramujos e fatores ambientais de risco).

2. Aumento da sensibilidade dos métodos diagnósticos com incorporação dos exames sorológicos como auxiliares no diagnóstico da esquistossomose e na decisão de estratégias mais seletivas para o tratamento dos casos.

3. Implantação de unidades geo-sentinelas (UGS), isto é, de unidade de saúde localizada próxima às regiões de risco, em áreas de autoctonia e/ou com grupos populacionais de risco, com capacidade para exercer a vigilância sentinela e buscas ativas, identificando precocemente casos assintomáticos e sintomáticos e todas as suas formas. A implantação de UGS assenta-se no apoio do Instituto Adolfo Lutz (IAL/CCD/SES-SP) para realização do exame sorológico pelo método de RIFI-IgM nos indivíduos atendidos nessas unidades e como diagnóstico complementar aos exames parasitológicos.

4. Implantação da Semana Estadual da Esquistossomose, uma vez ao ano, em todos os municípios paulistas, como atividade complementar à vigilância de rotina da doença. A finalidade da Semana é divulgar amplamente a doença na mídia, visando à população e profissionais de saúde, sobre sua importância, formas de transmissão, prevenção e tratamento e aumentar a captação precoce de casos/ portadores no estado de São Paulo. A ser realizada sempre no mês de maio, a ação deve ser dirigida a escolares e outros grupos populacionais de risco, incluindo indivíduos que residem em áreas de coleções hídricas potencialmente transmissoras da doença e com presença de contingentes migratórios procedentes de estados endêmicos. Essas ações são fundamentalmente de caráter educativo, apoiadas pela assistência médica e laboratórios. Em nível municipal, os indivíduos que se expuseram ao risco devem ser atendidos nos postos de saúde, realizando ou agendando consultas médicas e solicitando o exame parasitológico que permite o diagnóstico da doença ou outros complementares.Além disso, vários municípios realizam inquéritos parasitológicos, em escolares ou outros grupos populacionais de risco, visando a conhecer melhor ou atualizar a prevalência da doença e oferecer tratamento a essas populações.
5. Aprimoramento da investigação epidemiológica, do sistema de informação e monitoramento dos casos para identificação de medidas ambientais definitivas e interrupção da transmissão da doença.

6. Ênfase na atuação integrada e interinstitucional, nos vários níveis de vigilância envolvendo órgãos de vigilância ambiental, saneamento e de educação para atuações pontuais e definitivas no meio ambiente e de educação em saúde.

7. Implantação do Certificado de Eliminação da Doença Autóctone para os municípios que alcançarem a eliminação da autoctonia da esquistossomose, com criação de comitê para assessoria técnica e avaliação das atividades desenvolvidas e resultados.

\section{Semana Estadual da Esquistossomose}

Na I Semana da Esquistossomose, realizada de 25 a 30 de maio de 2009, foi divulgada mensagem de que, embora a esquistossomose ainda exista e possa ser também adquirida no estado de São Paulo, é possível, com algumas ações organizadas, impedir essa transmissão, evitar casos e eliminar a doença autóctone.

Durante a preparação do evento, vários resultados puderam ser obtidos pelos municípios. Entre outras atividades desencadeadas, destacaram-se a reorganização da rede laboratorial de apoio diagnóstico, levantamento de localidades de risco para doença e atualização do levantamento planorbídico, revisão de casos autóctones e de estatísticas, replanejamento dos estoques de medicamentos, maior integração com a rede de unidades básicas de saúde, inserção das escolas do ensino fundamental na campanha.

A população-alvo da campanha educativa foram, especialmente, os escolares e adultos jovens, residentes em áreas com coleções hídricas potencialmente de risco, o que representou cerca de 1 milhão de pessoas. A esse grupo foram dirigidas mensagens educativas sobre como se prevenir e evitar a doença ou de como proceder após exposição ao risco por meio de emissoras de rádio, televisão e jornais locais. A Semana desencadeou, ainda, inquéritos parasitológicos nessas regiões, esperando-se alcançar a meta de cerca de 20 mil pessoas, entre escolares e outros grupos de risco, além do atendimento à demanda espontânea de pessoas que procuraram as unidades básicas de saúde por terem se exposto ao risco, dentro ou fora do estado de São Paulo.

Cerca de 200 unidades de saúde foram implantadas como UGS para ser a referência da vigilância geográfica da doença, tendo sido planejada a realização, ao lado de exames parasitológicos, de cerca de 5 mil sorologias, ao longo do ano. Também foram distribuídos nos postos de saúde e escolas materiais educativos sobre a doença, como cartazes, folhetos e panfletos. 
Os resultados mais detalhados de todas as ações desenvolvidas ou desencadeadas estão ainda sendo computados por município e região de saúde. Isto permitirá a constituição de um banco de dados básicos, que em futuro breve subsidiará a avaliação das novas estratégias de captação de casos e das metas e prazos estabelecidos para a eliminação da esquistossomose autóctone no estado de São Paulo. ${ }^{a}$

a Para saber mais sobre a doença e sua vigilância, veja os documentos técnicos, material educativo, aulas e dados estatísticos produzidos pelo CVE, em:http://www.cve.saude.sp.gov.br/htm/hidrica/hidri_esquisto.htm e http://www.cve.saude.sp.gov.br/htm/hidrica/dados/Esquisto8108.xls. 